\title{
Accumulation and Transformation of Extractive Substances in Krasnodar Tea
}

\author{
$O$ Belous ${ }^{1, *}$ and $N$ Platonova ${ }^{1}$ \\ ${ }^{1}$ Subtropical Scientific Centre of the Russian Academy of Sciences, Yana Fabritsiusa st., 2/28, Sochi, \\ 354002, Russia
}

\begin{abstract}
It is important to create varieties with unique quality characteristics. However, a complete study of the processes of accumulation and transformation of the antioxidant complex in raw materials and finished (black and green) tea in humid condition of Russian has not been conducted. This article is devoted to the study of the features of the extractive substances of new selection forms of Krasnodar tea, breeding by scientists of the Subtropical Scientific Center. Comparison of tea by the content of components of the catechin complex showed that the new forms of tea selection Center is characterized by a high level of accumulation of various groups of catechins and the largest amount is epigallocatechingallate (from 42 to $66 \%$ ). The presence of active dynamics of caffeine, flavonoids and Ruthin in the raw material (3-leaf sprout), green and black tea. The variation of extractive substances in sprouts and ready-made tea is related to the weather conditions of vegetation, varietal characteristics of plants and processing conditions. All samples of the Center's selection have a rich phenolic complex, which is of interest as sources of resistance to the action of abiogenic stressors. They can be used for selecting plants with a highly effective antioxidant system.
\end{abstract}

\section{Introduction}

Tea is one of the richest sources of antioxidants. These are primarily catechins, as well as theaflavins, thearubigins, amino acids, flavonols, flavones, Gallic acid derivatives-tannin, etc. $[1,2,3,4]$. The quality of the finished tea depends on the composition of the substances that make up the raw material ( 2 or 3 -leaf sprouts). In green tea, the main contribution to antioxidant activity is made by catechins, and in black tea - by theaflavins and thearubigins. From their quantitative ratio depends on the quality of tea, high quality teas contain more of these substances than tea and low quality. When processing green tea leaves, the content of extractive (soluble) substances changes. Their content also depends on the plant variety, leaf age, harvest time, agrotechnical measures, and other factors.

Tea leaves, both fresh and processed, contain pigments (chlorophyll, carotenoids, anthocyanins, flavonoids), which determine the color of the tea. The quantitative content of flavonoids is one of the indicators of tea quality [5-9]. Therefore, for the primary

*Corresponding author: oksana191962@mail.ru 
assessment of the quality of plant raw materials, quantitative determination of the flavonoid content is often used.

An equally important role is played by such alkaloid-containing substances as caffeine (1, 3, 5-trimethylxanthine), theobromine and theophylline [10-14]. During the growing season, mainly caffeine $(2-3 \%)$ is formed and accumulated from alkaloid-containing compounds. The caffeine content changes during the growing season and during the processing of green tea leaves. In raw materials, the content of caffeine is the highest, but gradually decreases, since it combines with other tea substances (mainly proteins) and forms so-called caffeine tanate. As a result, green tea has more caffeine than black tea.

The metabolism of tea plants is based on the processes of accumulation and transformation of phenolic compounds (catechin complex, mainly (-) epigallocatechingallate), the content of which reaches $30 \%$ or more. Phenolic compounds (tannins, namely teotanin), are a complex mixture of the Gallic esters of catechins and the catechins themselves. Oxidized tetany tea infusion gives a yellow-brown or reddish color, astringency and taste. The content of phenolic compounds in tea, as well as all extractive substances, depends on many factors. Green tea leaves are characterized by changes in the content of phenolic compounds throughout the harvest season. But their content is also affected by the height of the plantation above sea level [15].

The Subtropical Scientific Center (Sochi, Russia) has a collection of highly productive varieties, as well as promising clones and hybrids of tea. This is a reliable basis for the reconstruction of existing and creation of new modern tea plantations in Russia. Special attention is paid not only to the yield and resistance of varieties to adverse conditions in the humid subtropics of Russia. It is important to create varieties with unique quality characteristics. As a result, on the basis of the Subtropical research Center for a long period of work on tea culture, varieties were created that are characterized by high quality products (cv. Sochi, Karatum, Matsestinsky, Vano, Adygeisky, etc.). However, only three biochemical components of tea raw materials were taken into account when evaluating them: tannins (tannins), the sum of water-soluble extractives and caffeine. A complete study of the processes of accumulation and transformation of the antioxidant complex in raw materials and finished (black and green) tea has not been conducted. Work in this direction was started in 2016 and continues to this day. This article is devoted to the study of the features of the chemical composition of new selection forms of tea, breeding by scientists of the Center: the dynamics of phenolic compounds; transformations occurring in the process of processing raw materials into ready-made tea.

\section{Material and methods}

\subsection{Plant material}

Objects of research: two varieties: cv. Colchida (control), cv. Sochi and four breeding forms - 582 (Record), 3823 (Start), 855 (Druzba), 2264 (Sputnic). All breeding samples belong to the large leaf morphological form of the Chinese tea group.

Production of green and black tea in the laboratory of plant physiology and biochemistry of the Subtropical Scientific Center conducted in compliance with all accepted technological processes. Raw materials for green tea went through the stages of steaming (for 3 minutes in the Koch apparatus at a temperature of 95-100 ${ }^{\circ} \mathrm{C}$ ), twisting, drying (in the drying cabinet in two steps: the first time at a temperature of $90-95{ }^{\circ} \mathrm{C}$ to a humidity of $18 \%$, then at a temperature of $80-90{ }^{\circ} \mathrm{C}$ to a residual humidity of 3-5 \%). When receiving black tea, the raw material was twisted, fermented and then dried in the same way as green tea. 


\subsection{Biochemical analysis}

Research of the catechin complex was performed by reverse-phase high-performance liquid chromatography. Standards used: catechin, epicatechin, epicatechin gallate, epigallocatechin, epigallocatechin gallate, gallocatechin, gallocatechin gallate, gallic acid. All reagents were chemically pure or analytical grade and contained more than $98 \%$ of the main substance. Extraction method was based on well-known method (ISO 14502-2:2005). The conditions of chromatographic analysis are: column temperature $40{ }^{\circ} \mathrm{C}$, flow 200 $\mu$ L.min-1, detection 210, 220, 230, 240, 250, 260, 280, $300 \mathrm{~nm}$. Elution was made in gradient mode from $0 \%$ to $40 \%$ B for $2800 \mu \mathrm{L}$. All measurements were performed in triplicate at the basic Institute of Chemical Biology and Fundamental Medicine, Siberian Branch of the Russian Academy of Sciences, Novosibirsk, Russia (scientific researcher A. Astanin and S. Sedykh [19]) and at the Department of organic chemistry state University of Saint Petersburg (scientific researcher L. Kartsova, V. Deev, and E. Bessonova [16]). Quantitative analysis of polyphenols (epicatechin (EC), epigallocatechin (EGC), gallocatechin (GC), epicatechin gallate (EGCG), epigallocatechin gallate (EGCG), Gallic acid (GA)) in the studied tea samples was performed at the maximum absorption wavelength of the analysed substances $(280 \mathrm{Nm})$ and their content was calculated in $1 \mathrm{~g}$ of dry tea [16].

The determination of caffeine (1, 3, 5-trimethylxanthine) was performed by reverse-phase high-performance liquid chromatography (HPLC). Tea sample (2.0 $\pm 0.01 \mathrm{~g})$, pre-homogenized, placed in a centrifugal tube with a capacity of $10 \mathrm{ml}$. Added to it $9 \mathrm{ml}$ of extractant (a mixture of water with acetonitrile 7: 2 by volume). Insured a tightly closed the vial plug. A control sample of tea $(2.0 \pm 0.01 \mathrm{~g})$, pre-homogenized, was placed in a $10 \mathrm{ml}$ centrifugal test tube. Added to it $9 \mathrm{ml}$ of extractant (a mixture of water with acetonitrile 7: 2 by volume) with $10 \mathrm{mg}$ of caffeine. The viola plug was tightly closed. Samples were placed in a water bath and caffeine was extracted at $60{ }^{\circ} \mathrm{C}$ for 30 minutes. The samples were cooled to room temperature, removing moisture from the outside. Extractive freezing in the determination of caffeine was performed using the method Bechterev [17] for $25 \mathrm{~min}$ at $4000 \mathrm{rpm}$. and a temperature of $\approx 30 \pm 1{ }^{\circ} \mathrm{C}$. The extracts were analysed using a chromatograph GC "Kristalllux" (Russia), equipped with a flame ionization detector and a capillary column Phenomenex (USA) $30 \mathrm{~m}$ long with an internal diameter of 0.32 $\mathrm{mm}$, and loaded with a stationary phase ZB-5.

Quantity analysis of flavonoids. Each sample was measured three times for both analyses of TFs and TRs. The $95 \%$ ethyl alcohol was used as extract to extract flavonoids from raw materials (Quality assurance checklist for small laboratories, 2009). In order to determine the TFs and the TRs, the method of spectrophotometry was used applying the analyser of PE-5400VI (Russia) in the wavelength range of $665 \mathrm{~nm}$ for TFs and $825 \mathrm{~nm}$ for TRs in contrast to water used as blind sample.

Bioflavonoid compounds with P-vitamin activity (Ruthin) was determined by titration in accordance with the method of vitamin analysis [18]. The quantitative determination of Ruthin is based on its ability to be oxidized by permanganate. As an indicator, indigocarmine is used, which reacts with permanganate after all Ruthin is oxidized.

\subsection{Statistical analysis}

Statistical processing of the experimental data was carried out using the ANOVA package in STATGRAPHICS Centurion XV (version 15.1.02, StatPoint Technologies) and MS Excel 2007. Statistical analysis included univariate analysis of variance (method of comparing averages using variance analysis, t-test) and variance analysis (ANOVA). The significance of difference between the means of the least significant difference (LSD) results with $\mathrm{p}<0.05$ was considered statistically significant. All experiments were 
performed in triplicate and the values were expressed as mean $\pm \mathrm{SD}$. The differences between the samples were assessed using unpaired t-test.

\section{Results}

\subsection{Catechin complex}

Comparison of tea by the content of components of the catechin complex showed that the new forms of tea selection Center is characterized by a high level of accumulation of various groups of catechins [19]: epicatechin, epigallocatechin, epicatechingallate, epigallocatechin gallate (table 1).

Table 1. Concentration of polyphenols in green tea, $\mathrm{mg} \cdot \mathrm{g}^{-1}$.

\begin{tabular}{|c|c|c|c|c|c|c|}
\hline Varieties/forms & GA & GC & EGC & EC & EGCG & ECG \\
\hline cv. 'Colchida' & $0.24 \pm 0.01$ & $2.82 \pm 0.01$ & $26.73 \pm 1.01$ & $5.72 \pm 0.00$ & $75.82 \pm 10.02$ & $4.15 \pm 0.01$ \\
\hline cv. 'Sochi' & $0.15 \pm 0.03$ & $2.28 \pm 0.08$ & $30.65 \pm 1.90$ & $6.40 \pm 0.02$ & $30.57 \pm 10.13$ & $2.41 \pm 0.30$ \\
\hline f. 3823 & $0.20 \pm 0.01$ & $2.72 \pm 0.76$ & $35.29 \pm 5.28$ & $6.24 \pm 0.49$ & $53.83 \pm 5.80$ & $3.30 \pm 0.47$ \\
\hline f. 582 & $0.32 \pm 0.24$ & $2.97 \pm 0.53$ & $27.60 \pm 3.31$ & $5.28 \pm 1.58$ & $36.90 \pm 1.17$ & $2.34 \pm 0.28$ \\
\hline f. 855 & $0.34 \pm 0.22$ & $2.93 \pm 0.07$ & $28.02 \pm 1.94$ & $6.02 \pm 2.21$ & $72.84 \pm 12.19$ & $4.57 \pm 0.35$ \\
\hline f. 2264 & $0.36 \pm 0.01$ & $2.32 \pm 0.04$ & $23.70 \pm 3.27$ & $4.21 \pm 0.17$ & $58.99 \pm 9.02$ & $2.99 \pm 0.14$ \\
\hline
\end{tabular}

The largest amount is epigallocatechingallate (from 42 to $66 \%$ of the total catechin content), in second place - epigallocatechin (on average, $31 \%$ of the total number of catechins). Both components are characterized by the highest antioxidant activity and the predominance of this group in breeding samples reflects their high value. The cv. Colchida, being a large-leaf tea, is characterized by a higher EGCG content $(75.8 \%)$. The low content of all catechin group substances is typical for cv. Sochi and form 582.

\subsection{Caffeine content (1, 3, 5-trimethylxanthine)}

The presence of active dynamics of caffeine in the raw material of tea (3-leaf sprout) depending on the weather conditions of the growing season was revealed. The greatest synthesis of caffeine in plants was observed in July (for varieties - from $24.63 \mathrm{mg}$. g-1 to $28.61 \mathrm{mg}$. g-1), the excess of its amount in comparison with the rest of the growing season is 1.6-2.3 times, which is very important (fig. 1). 


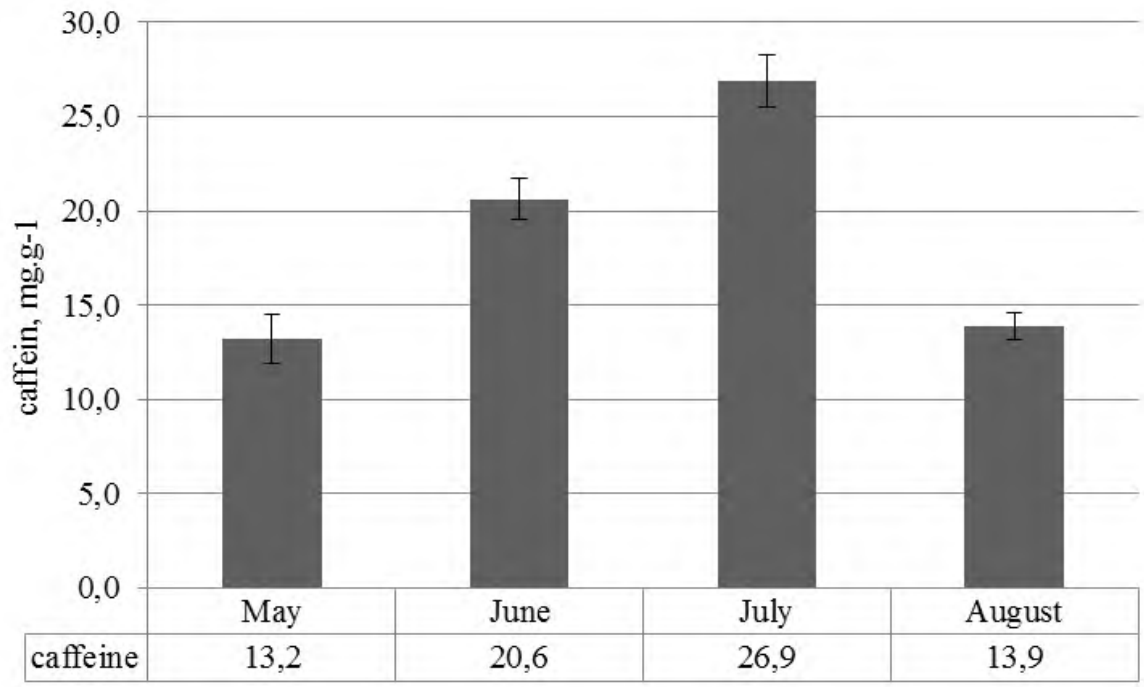

Fig. 1. Dynamics of caffeine in tea raw materials during the growing season, mg. g-1.

The least amount of caffeine is synthesized in June and August. The indicator is quite labile - the coefficient of variation is in the range of $29-52 \%$.

Table 2. Caffeine content in raw materials and green tea, mg. $\mathrm{g}^{-1}$.

\begin{tabular}{|c|c|c|c|c|c|c|c|}
\hline \multirow{2}{*}{ Varieties/forms } & \multicolumn{4}{|c|}{ Raw materials } & \multirow{2}{*}{$\mathrm{X} \pm \mathrm{m}$} & \multirow{2}{*}{$\mathrm{V}, \%$} & \multirow{2}{*}{$\begin{array}{c}\text { Green } \\
\text { tea }\end{array}$} \\
\hline & May & June & July & August & & & \\
\hline cv. Colchida & 20,61 & 13,22 & 26,93 & 13,21 & $18,50 \pm 6,62$ & 36 & 17,35 \\
\hline cv. Sochi & 16,33 & 13,70 & 24,63 & 14,46 & $17,28 \pm 5,03$ & 29 & 16,45 \\
\hline f. 3823 & 15,68 & 11,07 & 27,10 & 9,95 & $15,95 \pm 7,84$ & 49 & 13,42 \\
\hline f. 582 & 19,26 & 13,31 & 28,61 & 10,75 & $17,98 \pm 7,93$ & 44 & 15,20 \\
\hline f. 855 & 13,52 & 11,04 & 26,73 & 11,90 & $15,80 \pm 7,36$ & 47 & 13,83 \\
\hline f. 2264 & 12,07 & 12,98 & 25,38 & 7,62 & $14,51 \pm 7,61$ & 52 & 13,89 \\
\hline
\end{tabular}

When processing raw materials into ready-made tea, there is a slight destruction of caffeine, its amount decreases insignificantly (table 2). It is shown that the raw materials of breeding samples contain less caffeine (on average from 14 to $17 \mathrm{mg}$. g-1). Despite the fact that the chemical relationship between tea caffeine and tannins neutralizes its effect on the human body (compared to coffee caffeine), the lower caffeine content in new forms of tea makes them more attractive against the background of the caffeine-rich cv. Colchida (table 2).

\subsection{Content of flavonoids}

We have noted the active dynamics of flavonoids during the growing season. From May to August, the content of flavonoids in raw materials increases sharply, then there is a smoother drop (fig. 2). Peak of theaflavin and thearubigin synthesis occurs in June (0.094 and $1.194 \mathrm{mg} / \mathrm{g}$, respectively). The accumulation of flavonoids is a very dynamic trait, with an average variability of $26 \%$ (TFs) - $37 \%$ (TRs), depending on genotypic features. 


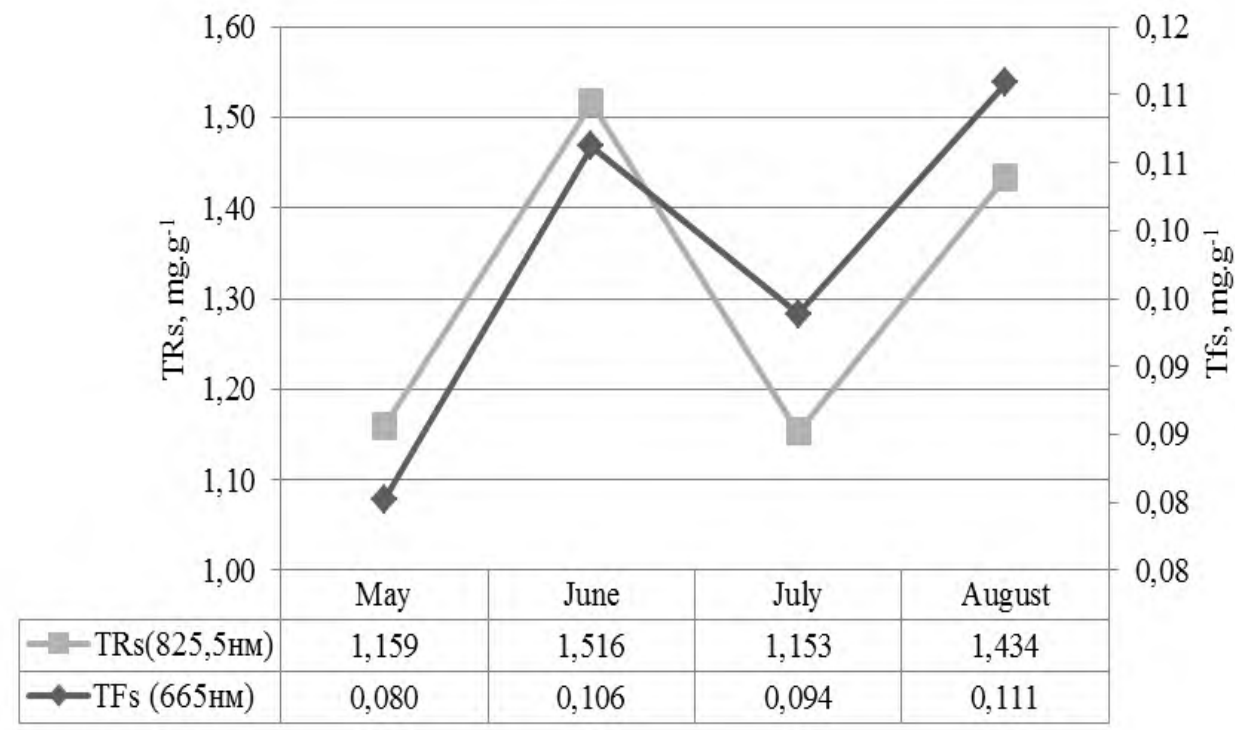

Fig. 2. Dynamics of flavonoids in tea raw materials during the growing season, mg. g-1.

We conducted a research to identify changes in the quantitative parameters of flavonoids during the processing of raw materials into black and green tea (table 3).

Table 3. The content of flavonoids in raw materials and finished black tea.

\begin{tabular}{|c|c|c|c|c|c|c|c|c|}
\hline \multirow{2}{*}{ Varieties/forms } & \multicolumn{4}{|c|}{ Raw materials } & \multicolumn{2}{c|}{ Green tea } & \multicolumn{2}{c|}{ Black tea } \\
\cline { 2 - 10 } & $\begin{array}{c}\text { TFs } \\
(665 \mathrm{HM})\end{array}$ & $\begin{array}{c}\text { V, } \\
\%\end{array}$ & $\begin{array}{c}\text { TRs } \\
(825,5 \mathrm{HM})\end{array}$ & $\begin{array}{c}\text { V, } \\
\%\end{array}$ & TFs & TRs & TFs & TRs \\
\hline cv. Colchis & $0.10 \pm 0.04$ & 31 & $1.49 \pm 0.66$ & 40 & $0.04 \pm 0.01$ & $0.72 \pm 0.28$ & $0.13 \pm 0.04$ & $1.85 \pm 0.76$ \\
\hline cv. Sochi & $0.08 \pm 0.02$ & 28 & $1.08 \pm 0.34$ & 41 & $0.04 \pm 0.02$ & $0.71 \pm 0.39$ & $0.08 \pm 0.03$ & $1.11 \pm 0.41$ \\
\hline f. 3823 & $0.10 \pm 0.01$ & 21 & $1.27 \pm 0.26$ & 34 & $0.04 \pm 0.01$ & $0.60 \pm 0.23$ & $0.10 \pm 0.01$ & $1.12 \pm 0.02$ \\
\hline f. 582 & $0.12 \pm 0.03$ & 27 & $1.60 \pm 0.40$ & 32 & $0.04 \pm 0.02$ & $0.70 \pm 0.32$ & $0.13 \pm 0.03$ & $1.71 \pm 0.46$ \\
\hline f. 855 & $0.11 \pm 0.02$ & 24 & $1.35 \pm 0.31$ & 34 & $0.04 \pm 0.02$ & $0.63 \pm 0.41$ & $0.10 \pm 0.02$ & $1.17 \pm 0.10$ \\
\hline f. 2264 & $0.11 \pm 0.04$ & 27 & $1.53 \pm 0.58$ & 41 & $0.03 \pm 0.01$ & $0.53 \pm 0.13$ & $0.14 \pm 0.03$ & $1.94 \pm 0.46$ \\
\hline
\end{tabular}

Studies have shown that about $47 \%$ of flavonoids are destroyed in the production of green tea. However, fermentation processes start the process of their synthesis and already in black tea the number of flavonoids is almost similar to their content in the raw material. There were no differences in the content of theaflavins in green tea by variety; the smallest number of thearubigins was found in the selection sample 2264. However, this form is characterized by active metabolic processes, which leads to the active synthesis of theaflavins (0.14 mg. g-1) and thearubigins (1.94 mg. g-1). The smallest number of flavonoids in both raw materials and black tea differs from cv. Sochi.

\subsection{Bioflavonoid compounds with P-vitamin activity (Ruthin)}

As we have shown that depending on the season of tea leaf collection, the content of Ruthin in green tea ranges from 35.7 to $41.2 \mathrm{mg}$. g-1, and in black tea - within $16.6-20.4 \mathrm{mg}$. g- 1 , which is 2 times lower than in green unfermented tea (fig. 3). 


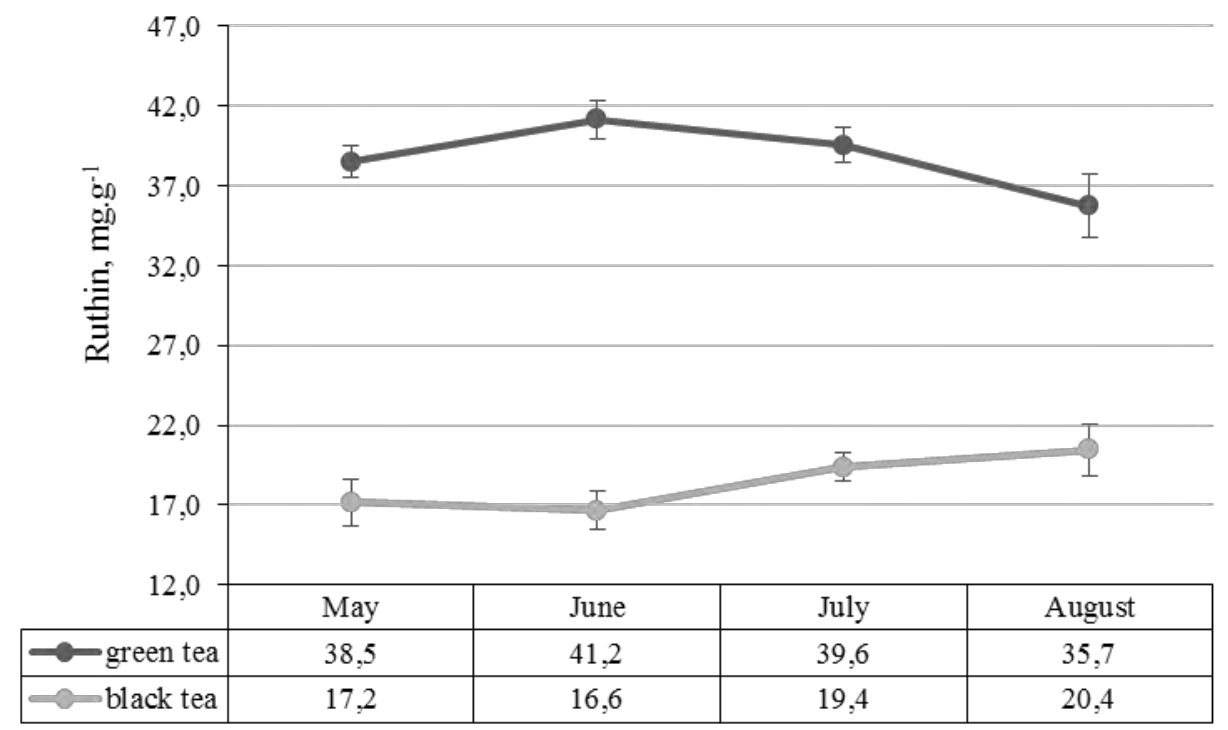

Fig. 3. Dynamics of bioflavonoid compounds with P-vitamin activity (Ruthin) in the raw material of tea during the growing season, $\mathrm{mg}$. g-1.

Genotypic features have no less influence on the content of vitamin P (table 4).

Table 4. Content of bioflavonoid compounds with P-vitamin activity in tea of selected forms and varieties, mg.g ${ }^{-1}$.

\begin{tabular}{|c|c|c|c|c|}
\hline Varieties/forms & Green tea & V,\% & Black tea & V,\% \\
\hline cv. Kolchida & $30.80 \pm 1.2$ & 4 & $11.47 \pm 0.3$ & 3 \\
\hline cv. Sochi & $38.27 \pm 1.1$ & 3 & $10.27 \pm 0.2$ & 2 \\
\hline f. № 3823 & $37.73 \pm 1.1$ & 3 & $12.07 \pm 0.2$ & 2 \\
\hline f. № 582 & $40.40 \pm 1.0$ & 2 & $11.80 \pm 0.5$ & 4 \\
\hline f. № 855 & $42.27 \pm 1.2$ & 3 & $13.73 \pm 0.4$ & 3 \\
\hline f. № 2264 & $39.07 \pm 1.3$ & 3 & $12.40 \pm 0.2$ & 2 \\
\hline
\end{tabular}

A lower content of Ruthin in green tea was observed for the selection sample 3823. A high number of bioflavonoids with P-vitamin activity is typical for form 855 (table 4). In black tea, the least routine is in the sample obtained from raw materials. However, there is no big difference between varieties and forms. As can be seen from table 4, the variability of the indicator is quite low - on average 3-4 \%, which is a good selection and characteristic feature.

\section{Discussion}

Within the black sea coast of the Krasnodar territory, which according to natural and climatic conditions is classified as a zone of humid subtropics, active vegetation of tea plants (June -August) takes place with a lack of precipitation in a long (two months or more) drought. In this regard, the main direction of selection work in the Subtropical research center is to obtain locally adapted varieties of subtropical crops, which requires the search for source material with valuable breeding, biological and economic indicators that 
allow for targeted and effective selection. Phenolic compounds (flavonoids, catechins) play an important role in adaptation to adverse environmental conditions).

\subsection{Catechin complex}

Catechins are reduced forms of flavonoids containing one or more hydroxyl groups that can be rapidly oxidized and polymerized. The more polyphenols in dry tea, the higher the quality of the infusion, the better the color, tartness and aroma of the drink.

Catechin content is a fairly dynamic process that depends on a large number of factors: weather conditions, agricultural activities, plant varieties, etc. The synthesis of phenolic compounds is largely due to the influence of light, especially during periods of strong insolation.

Green tea retains the chemical composition characteristic of fresh tea leaves, which contains stereoisomers of the catechin group [20]. The total content of catechins in green tea was $0.32 \mathrm{mg} . \mathrm{g}^{-1}$ [9]. Black tea contains less Monomeric catechins, since during fermentation they are polymerized to form oligomeric theaflavins (yellow-orange) and thearubigins (red-brown) [21]. Since green tea is the most catechin-rich beverage, we analyzed green tea specifically. There was a lower value of catechin complex components in tea collected in August, compared to the same varieties collected in July. This may indicate a possible correlation between the content of catechin groups and the time of tea collection [16]. In addition, we noted that the variability of the indicator for the collection time for different components of the catechin complex is different. Gallic acid - GA is the most dynamic $(\mathrm{V}=29 \%)$. This is not accidental, since this compound easily enters into oxidative reactions. Under temperature stress, plants accumulate a large amount of peroxides, which can affect the processes of synthesis/transformation of Gallic acid. GA variability also depends on the genotypic features of breeding samples. Gallic acid is most static in cv. 'Sochi', forms f. 582 and 855 . The remaining compounds of the catechin complex have low variability both in the collection periods and in the varieties $(\mathrm{V}=9$ $13 \%$ ). This fact may have diagnostic significance for the selection of donors of useful traits.

\subsection{Caffeine content (1, 3, 5-trimethylxanthine)}

Tea contains one of the varieties of caffeine - Thein (caffeine thanate). The peculiarity of Thein is a milder effect on the human body [22]. Since caffeine is present in combination with the tannin of tea, it is not extracted completely when brewed and the drink acts on the body more gently. At the same time, unlike caffeine, Thein does not accumulate in the body [23-24].

It is known that the content of caffeine in raw materials is a dynamic sign. The beginning of vegetation of tea plants in the humid subtropics of Russia falls on April. In May, there is an active growth of sprouts, but temperature conditions do not allow it to accumulate enough biologically active substances in the sprouts. Therefore, May tea in the subtropics of Russia has a poor chemical composition [19, 25-26]. In June, the tea plants go into a phase of relative summer rest, during which the metabolic processes are inactive, which leads to a slowdown in the synthesis of caffeine in the raw material and its amount increases slightly. Active synthesis occurs in the second wave of growth (in the conditions of subtropical Russia-this is July), which is characterized by a high content of many extractive substances in sprouts, including caffeine (on average $26.9 \mathrm{mg}$. g-1). In August synthesis is inhibited due to high air temperatures against the background of prolonged drought and plant stress.

When you get green tea (weakly fermented), there is a slight destruction of caffeine, so green tea contains the same amount of caffeine as raw materials. Since caffeine stimulates 
the nervous system, teas and tea plants become popular as sources of raw materials with a low content of caffeine [27-28]. In this regard, the Center's selection samples containing less caffeine than the control Colchis variety are more promising.

\subsection{Content of flavonoids}

The analysis showed that the greatest influence on the synthesis of both groups of flavonoids has the amount of precipitation (table 5). Both groups of flavonoids are closely related to each other.in the production of tea, there is a mutual conversion of theaflavins into thearubigins, which depends on the passage and duration of the fermentation process.

Table 5. Coefficients of pair correlation between flavonoid content and hydrothermal factors of the growing season.

\begin{tabular}{|c|c|c|c|}
\hline Parameters & Temperature, ${ }^{\circ} \mathrm{C}$ & $\begin{array}{c}\text { The amount of } \\
\text { precipitation, } \mathrm{mm}\end{array}$ & TRs $(825.5 \mathrm{Hm})$ \\
\hline TRs $(825.5$ нм $)$ & -0.49 & 0.99 & - \\
\hline TFs $(665$ нм $)$ & -0.17 & 0.89 & 0.94 \\
\hline
\end{tabular}

Flavonoids are very labile compounds and easily transform from one compound to another [22-29]. Therefore, there is a direct relationship between the quality of raw materials and the content of flavonoids in tea. The essence of black tea technology is to accelerate the conversion of substances by activating the action of enzymes. This causes changes in the ratio and number of flavonoids that are part of the tea raw material. In the production of green tea, the activity of enzymes is suppressed, which is achieved by steaming sprouts. The main amount of theaflavins (TFs) and thearubigins (TRs) is formed during the fermentation of tea. Therefore, green tea contains less theaflavins than raw materials and black tea, since they are destroyed by the synthesis of thearubigins.

Theaflavins are unstable compounds and easily pass into thearubigins during enzymatic oxidation or temperature exposure [30-31]. The chemical structures of thearubigin and theaflavin are similar, but theaflavin is more active, but less resistant to destruction, than thearubigin, which it turns into during oxidation [30]. Fully fermented black teas had a trace of EGCG, but contained theaflavins [20]. Research conducted by many scientists has established that any blend of tea should have a ratio of theaflavins and thearubigins not lower than $1: 16$, and in higher-quality tea 1:10 [3,32-33]. This ratio is now accepted by international rules as an indicator of the quality of tea. According to this indicator, all Krasnodar tea, as well as tea from experimental plants, meets international requirements.

\subsection{Bioflavonoid compounds with P-vitamin activity (Ruthin)}

Ruthin (vitamin P) is an important component of the antioxidant system of tea plants. It not only takes part in the main redox reactions, but also increases the absorption of ascorbic acid [24, 34-38]. In addition, Ruthin itself is a strong antioxidant, which makes it preferable to varieties with a high content of Ruthin. As research has shown Klykov [39] on buckwheat, the increased content of Ruthin is typical for plants with red leaf color. The same pattern is observed in relation to tea plants. Selection sample 855 is characterized by a reddish color of leaves and sprouts (table 2). that is why the content of Ruthin in the finished tea of this form is higher than in other plants. During processing, the content of Ruthin changes slightly, so in green tea, its amount is similar to raw materials. However, in black tea, the fermentation process, which consists in the active oxidation of biochemical components, leads to the destruction of Ruthin and its amount drops noticeably. 


\section{Conclusion}

A comprehensive analysis of the biochemical composition of tea was carried out. The variation of all phenolic components in both sprouts and ready-made tea was revealed. This is due to both the varietal characteristics of plants and processing conditions. In the production of unfermented (green) tea, there is no fermentation process, which is the most important technological method in the production of black tea. This allows green tea to retain almost all of the water-soluble vitamins that inhibit lipid peroxidation in cell membranes. In addition, the differences are due to the influence of weather conditions of vegetation. It is known that elevated temperatures (in the humid subtropics of Russia in the summer is often observed around $30{ }^{\circ} \mathrm{C}$ and above) activate oxidative processes in the plant cell in response to the formation of reactive oxygen species. The mechanism of adaptation is activated with an increase in the number of antioxidants. The mechanism can be explained by non-specific antioxidant properties of low-molecular compounds that can intercept free radicals and reactive oxygen species. Plants with a high content of antioxidants are of undoubted interest not only as carriers of stable characteristics, but also as sources of biologically active substances. All samples of the Center's selection have a rich phenolic complex, which is of interest as sources of resistance to the action of abiogenic stressors. They can be used for selecting plants with a highly effective antioxidant system. In addition, having an increased content of biologically active substances, plants are high-quality raw materials for creating functional beverages based on promising forms of selection of the Subtropical research center.

\section{References}

1. Roginsky V A 1988 Phenolic antioxidants. Reactivity and efficiency (Moscow: Nauka) p 247

2. Zenkov K N, Kandalintseva N V, Lankin V E, Menshikova E B, Prosenko A E 2003 Phenolic antioxidants (Novosibirsk: Siberian branch of the Russian Academy of medical Sciences) p 343

3. Palanivel M, Venkateswaran G, Sathish G, Shanmugaselvan V 2020 Int. J. of Advanced Engineering Research and Science 7(4) 403

4. Henning S M, Niu Y, Lee N H, Thames G D, Minutti R R, Wang H, Go V L W, Heber D 2004 The American Journal of Clinical Nutrition 80(6) 558

5. Wan X, Li D, Zhang Z, Xia T, Ling T, Chen Q 2015 J. Tea Sci. 35(1) 1

6. Potapovich A I, Kostyuk V A 2003 Biochemistry 68(5) 632

7. Ivanova A V., Gerasimova E L, Gazizullina E R, Popova K G, Matern A I 2017 J. of Analytical Chemistry 72(4) 415

8. Zaprometov M N 1993 Phenolic compounds: Distribution, metabolism and functions in plants (Moscow: Nauka) p 271

9. Zaprometov M N 1993 Plant Physiology 40(6) 921

10. Leong L K, Su Y, Chen R, Zhang Z, Huang Y, Chen Z-Y 2001 J. Nutr. 1312248

11. Valiulina D F, Makarova N V 2018 Bulletin of the Voronezh state University of engineering technologies $\mathbf{8 0 ( 3 )} 1104$

12. Wright L P 2005 Biochemical analysis for identification of quality in black tea (Camellia sinensis). Dr. phil. sci. (Biochemistry) diss (Pretoria: University of Pretoria) p 216

13. Chowdhury P, Sahuc M-E, Rouille Y, Riviere C, Bonneau N, Vandeputte A et al 2018 
PLOS ONE 13(11)

14. Ai Z, Zhang B, Chen Y, Ni D 2017 J. Food Sci. Tech. Mys. 54(06) 1212

15. Platonova N, Belous O, Ostadalova M 2017 Subtropical and ornamental gardening 61 180

16. Kartsova L A, Deev V A, Bessonova E A, Belous O G, Platonova N B 2019 Analytics and control 23(3) 377

17. Bekhterev V N Patent EP3357873 2019 Published in European Patent Bulletin

18. Voskresenskaya O L, Alyabysheva E A, Polovnikova M G 2006 Large workshop on Bioecology (Yoshkar-Ola: Mar.state University) 107

19. Platonova N, Astanin A, Sedykh S, Samarina L, Belous O 2019 Potravinarstvo Slovak J. of Food Sciences 13(1) 32

20. Lin L Z, Chen P, Harnly J M 2008 J. Agric. Food Chem. 56(17) 8130

21. Nguyen Ngoc Tram, Phan Phuoc Hien, Huynh Ngoc Oanh 2015 J. of Food and Nutrition Sciences 3(1-2) 88

22. Afonina S N, Lebedeva E N, Setko N P 2017 Orenburg medical bulletin 4(20) 17

23. Vinson J A 2000 Biofactors 327

24. Sharangi A B 2009 Food Res. Int. $42 \quad 529$ https://doi.org/10.1016/j.foodres.2009.01.007

25. Belous O, Platonova N2018 American J. of Plant Sciences 9(09) 1771

26. Platonova N B, Belous O G 2020 Subtropical and decorative gardening 72116

27. Sriram P L 2016 Int. J. of Research in Science and Engineering 2164

28. Jin J-Q, Chai Y-F, Liu Y-F, Zhang J, Yao M-Z, Chen L 2018 J. of Agricultural and Food Chemistry 66(43) 11311

29. Li Y, Shibahara A, Matsuo Y, Tanaka T, Kouno I 2010 J. Nat. Prod. 73(1) 33

30. Sharma E, Joshi R, Gu-lati A 2017 Food Chemistry 1(242) 601

31. Balentine D A, Wiseman S A, Bouwens L C M 1997 Critical Reviews in Food Science and Nutrition 37(8) 693

32. Kang Y R, Park J, Jung S K, Chang Y H 2017 Food Chem. $245943-950$

33. Li X, Zhou R, Xu K, Xu J, Jin J, Fang H, He L 2018 Molecules 231010

34. Gulati A, Ravindranath S D 1996 J. Sci. Food Agric. 71231

35. Tanaka T 2008 Yakugaku Zasshi 128(8) 1119

36. Sinija V R, Mishra H N 2008 J. of Nutritional Environmental Medicine 17(4) 232

37. Skotnicka M, Chorostowska-Wynimko J, Jankun J, Skrzypczak-Jankun E 2011 Central-European J. of Immunology 36(4) 284

38. Ferreira M C L, Lima L N, Cota L H T, Costa M B, Orsi P M E, Espíndola R P, Albanez A V, Rosa B B, Carvalho M G S, Garcia J A D 2020 Brazilian J. of Medical and Biological Research $\mathbf{5 3}$

39. Klykov A G 2010 Agricultural Biology 349 